\title{
The PTPN22 C1858T (R620W) functional polymorphism in inflammatory bowel disease
}

\author{
Younes Zaid ${ }^{1 *}$, Nezha Senhaji ${ }^{2}$, Fatima Zahra Bakhtaoui ${ }^{3}$, Aurora Serrano ${ }^{4}$, Nadia Serbati ${ }^{2}$, Mehdi Karkouri ${ }^{3}$, \\ Wafaa Badre ${ }^{5}$, Mounia Oudghiri, Javier Martin ${ }^{4}$ and Sellama Nadifi
}

\begin{abstract}
Objective: In view of the discrepant data regarding the association between the protein tyrosine phosphatase nonreceptor 22 (PTPN22) rs2476601 (R620W, 1858C $\rightarrow$ T) polymorphism and susceptibility to autoimmune diseases including inflammatory bowel diseases (IBD), we investigated whether this functional single-nucleotide polymorphism influences IBD risk in a group of Moroccan patients.

Results: This is the first report on the prevalence of PTPN22 (R620W) variant in a Moroccan cohort. No evidence of statistically significant differences was observed when the PTPN22 (R620W) allele and genotype distribution among IBD, Crohn's disease (CD), ulcerative colitis (UC) patients and healthy controls were compared. The frequency of the variant allele in healthy subjects was $1.77 \%$ compared to $2.56 \%$ in the IBD patients and $1.85 \%$ in CD patients. Furthermore, the frequency of this allele was increased in UC patients compared to controls $(4.17 \%$ vs. $1.77 \%, \mathrm{OR}=2.42$, $95 \% \mathrm{Cl} 0.82-7.08 ; \mathrm{P}=0.09)$, but the difference was not statistically significant. Our data suggest a lack of association between PTPN22 R620W variant and IBD susceptibility in Moroccan patients.
\end{abstract}

Keywords: PTPN22, IBD, CD, UC, Morocco

\section{Introduction}

The inflammatory bowel diseases (IBD) are chronic inflammatory disorders of the gastrointestinal tract that manifests as Crohn's disease (CD) and Ulcerative colitis (UC), clinically characterized by periods of remission punctuated by episodes of clinical disease activity [1]. IBD are likely thought to result from interplay of several immunological, environmental, genetic, and life-style factors that may proceed to a dysregulated mucosal immune response to the gut microflora [2].

Dissimilarities are observed between CD and UC in terms of disease manifestation. This Heterogeneity may reflect differences in the pathogenesis between the two forms of IBD. There is some support for the concept that differences between CD and UC may be in large measure genetically determined [3].

\footnotetext{
*Correspondence: younes_zaid@yahoo.ca

${ }^{1}$ Research Center of Abulcasis University of Health Sciences, Rabat, Morocco

Full list of author information is available at the end of the article
}

As in most autoimmune diseases, genetic susceptibility to IBD is heterogeneous and complex and presumably implies multiple genes of relatively low penetrance [4]. Genome-wide scans and linkage analyses have identified a number of genetic markers as possible IBD susceptibility loci, with some of them observed uniquely in UC or $\mathrm{CD}$, and others common to both disorders [5].

Analysis of selected candidate genes mapping within susceptibility regions revealed variant in the PTPN22 (protein tyrosine phosphatase non-receptor 22) gene as being associated with IBD [6]. Located on chromosome 1p13, PTPN22 encodes an intracellular protein tyrosine phosphatase (PTP) expressed in T lymphocytes, the Lymphoid-tyrosine phosphatase (LYP) with a molecular weight of $110 \mathrm{kDa}$ [7], which is implicated in maintaining the resting phenotype of lymphocytes [8].

The intracellular PTP, LYP, contains a catalytic N-terminal and non-catalytic $\mathrm{C}$ terminus domains with four proline-rich motifs [9]. LYP is found to be physically bound with high affinity to the SH3 domain of the Src kinase (CSK) through one prolinerich motif (referred to as $\mathrm{P} 1)$. These interactions regulate the phosphorylation 
state of the kinases LCK, Fyn and Zap-70, all known to be important in $\mathrm{T}$ cell receptor signaling [10].

Protein tyrosine phosphatase are critical regulators of many different aspects of T-cell physiology. In conjunction with protein tyrosine kinases (PTKs), PTPs regulate the reversible phosphorylation of tyrosine residues in proteins and thereby play important roles in T-cell signal transduction [11].

Abnormalities in tyrosine phosphorylation have been demonstrated to be involved in the etiological and pathogenic process of a range of diseases in which the phenotypic spectrum includes an aberrant immune response. Thereby, $\mathrm{T}$ cells displaying dysregulated tyrosine phosphorylation, and hence abnormal $\mathrm{T}$ cell activation, would predictably mediate the pathological process in several autoimmune diseases.

Several lines of evidence suggest that the functionally relevant PTPN22 (R620W) polymorphism may lower the threshold of T-cell activation and hence may heighten an individual carrier's risk for human autoimmune and infectious disorders [11].

A missense single nucleotide polymorphism (SNP) with functional influence, the R620W (rs2476601, $1858 \mathrm{C}>\mathrm{T}$ ) in exon 14 of PTPN22 gene, changes the amino acid at position 620 from an arginine (R) to a tryptophan (W). The latter variant disrupts the interaction between LYP and CSK, which prevents formation of the complex and, therefore, suppression of T-cell activation [12]. In vitro experiments have shown that $620 \mathrm{~W}$-allele binds less efficiently to CSK than R-allele suggesting that $\mathrm{T}$ cells expressing the risk allele may be hyperresponsive [13]. Consequently, individuals carrying this allele may be prone to multiple autoimmune disorders.

Functional studies of mutant Lyp in $\mathrm{T}$ cells showed that the PTPN22 T1858 acts in an autosomal dominant fashion and confers significant predisposition to autoimmunity even when present as a single copy [14] with increased clinical penetrance in homozygous carriers [15].
Investigation of PTPN22 R620W (C1856T) association with $\mathrm{CD}$ was first reported by van Oene $M$ et al. [16] subsequent studies have had divergent results and showed strong evidence of ethnic differences. An interesting feature of the PTPN22 R620W (C1856T) polymorphism is the wide variation of allele frequency among different populations, i.e. there is a gradient of increasing frequency in white European populations. In most American-European populations, allele frequencies range between 8 and 9\%. In addition, the PTPN22 620W allele was reported to be absent from Asian and African populations $[13,12]$. These large allele frequency differences in the various populations emphasize the importance of careful case-control matching for genetic studies, particularly in the North African population where considerable population heterogeneity has been reported [17]. Accordingly, In view of the discrepant data regarding the distribution of the risk alleles of PTPN22 R620W we tested for the first time the association of the polymorphism with the susceptibility to IBD in a cohort of Moroccan patients in order to determine quantitatively the risk of CD and UC with the rs2476601 variant under an allelic, recessive and dominant model.

\section{Main text \\ Results}

We examined the possibility that the PTPN22 $1858 \mathrm{~T}$ variant might predispose to IBD, by genotyping 135 patients with $C D$ and 60 subjects with UC and 311 controls with Moroccan origin. Genotype assignment was successful in $>95 \%$ of samples tested.

The sample size used in the IBD analyses had 50\% power to detect the effect of the SNP conferring an odd ratio 1.7 at the $5 \%$ significance level.

Allele and genotype distributions for the PTPN22 polymorphism in cases and controls are summarized in Tables 1 and 2. Overall, we observed no evidence of genetic association between the PTPN221858T polymorphism and IBD susceptibility. When comparing patients

Table 1 Minor allele frequencies of PTPN22 (rs2476601) genetic variant in IBD patients and healthy controls from Morocco

\begin{tabular}{lllll}
\hline SNPID & Subgroup & Number of alleles & MAF \% & Allele test \\
\cline { 3 - 5 } & & & OR [95\% Cl] \\
\hline PTPN22 rs2476601 & Controls $(n=311)$ & $11 / 611$ & 1.77 & \\
& IBD $(n=195)$ & $10 / 380$ & 2.56 & $1.46[0.61-3.48]$ \\
& CD $(n=135)$ & $5 / 265$ & 1.85 & $1.05[0.36-3.05]$ \\
& UC $(n=60)$ & $5 / 115$ & 4.17 & $2.42[0.82-7.08]$
\end{tabular}

Frequencies of the PTPN22 allele between CD patients, UC patients, and IBD patients, were not significantly different compared to healthy controls Italic value indicates trend of association $(P=0.09)$

SNPID Single nucleotide polymorphism identifiant, IBD inflammatory bowel disease, CD Crohn's disease, UC ulcerative colitis, OR odds ratios, PTPN22 protein tyrosine phosphatase non-receptor type 22, MAF Minor Allele Frequencies 
Table 2 Genetic models and genotypes distribution in patients and controls

\begin{tabular}{|c|c|c|c|c|c|c|c|c|c|}
\hline \multirow[t]{2}{*}{$\begin{array}{l}\text { Gene } \\
\text { SNP }\end{array}$} & \multirow[t]{2}{*}{ Group } & \multirow[t]{2}{*}{$1 / 2$} & \multicolumn{3}{|c|}{ Genotype, N (\%) } & \multicolumn{2}{|c|}{$\begin{array}{l}\text { Dominant model } \\
\text { Genotype } 11+12 \text { vs. } 22\end{array}$} & \multicolumn{2}{|c|}{$\begin{array}{l}\text { Recessive model } \\
\text { Genotype } 11 \text { vs. } 12+22\end{array}$} \\
\hline & & & AA & AG & GG & OR $(95 \% \mathrm{Cl})$ & P-value & OR $(95 \% \mathrm{Cl})$ & P-value \\
\hline \multirow[t]{4}{*}{ PTPN22 rs2476601 } & Controls & $\mathrm{A} / \mathrm{G}$ & $1(0.32)$ & $9(2.89)$ & 301 (96.78) & & & & \\
\hline & $\mathrm{IBD}$ & & $1(0.51)$ & $8(4.10)$ & $186(95.38)$ & $1.45[0.58-3.65]$ & 0.42 & $1.59[0.09-25.7]$ & 0.74 \\
\hline & $C D$ & & $0(0.00)$ & $5(3.70)$ & $130(96.30)$ & $1.15[0.38-3.45]$ & 0.79 & NA & NA \\
\hline & UC & & $1(1.69)$ & $3(5.08)$ & $56(94.91)$ & $2.15[0.65-7.09]$ & 0.20 & $5.25[0.32-85.18]$ & 0.24 \\
\hline
\end{tabular}

No association was seen with PTPN22 SNP under dominant model AA+AG vs. GG (11+12 vs. 22) or recessive AA vs. AG + GG (11 vs. $12+22)$ either for the IBD group or when dividing into $C D$ and UC groups

PTPN22 protein tyrosine phosphatase non-receptor type 22, SNP Single nucleotide polymorphism, IBD inflammatory bowel disease, CD Crohn's disease, UC ulcerative colitis, $O R$ odds ratios

with the control group, frequencies of the PTPN22 risk allele were not significantly different: the frequency of the variant $1858 \mathrm{~T}$ allele amounted to $1.85 \%$ in CD cases, $2.56 \%$ in the combined IBD, and $1.77 \%$ in healthy controls. Noteworthy, the frequency of the PTPN22 620-W allele tended to be higher in UC cases than in controls, without reaching a significant difference $(4.17 \%$ vs. $1.77 \%$, OR: $2.42,95 \%$ CI $0.82-7.08 ; \mathrm{P}=0.09$ ).

Similarly, no statistically significant differences were observed when the 1858C $>\mathrm{T}$ SNP genotype distribution between CD patients, UC patients, and healthy controls was compared. Furthermore, combined phenotype of CD and UC (IBD patients) displayed no significant difference in genotype frequencies of PTPN22 $1858 \mathrm{C}>\mathrm{T}$ polymorphism compared with controls. Worth mentioning that, the homozygous genotype for the variant allele was absent in CD patients.

Regarding the possible effects of genetic models on disease risk, no association was seen with PTPN22 SNP under recessive AA vs. AG + GG or dominant model $A A+A G$ vs. GG, either for the IBD group as a whole or when dividing into $C D$ and $U C$ groups.

\section{Discussion}

The PTPN22 (R620W) SNP was first reported to be associated with type 1 diabetes [18] and later with rheumatoid arthritis [13], systemic lupus erythematosus [19], autoimmune thyroid disease [20] and as such with several other autoimmune diseases [21]. However, the mechanism by which altered 620WPTPN22 function in lymphocytes might contribute to the diverse PTPN22associated pathologies remains not fully determinate. On the other hand, the genetic implication of this variant could not be evidenced in some inflammatory diseases such as psoriasis, multiple sclerosis and Behcet's disease $[22,23]$. These differences may be the result of different adaptive immune system pathogeneses, in particular regarding $\mathrm{T}$ cells, in these disorders.
Given these data, PTPN22 (R620W) polymorphism can be considered as good candidate gene in the study of genetically determined IBD. In view of the etiologic and pathogenic relevance of PTPN22, we sought to assess the potential role of the $620 \mathrm{~W}$ as a candidate susceptibility allele for IBD, CD and UC in a case-control study of Moroccan patients.

Our study revealed no direct association of the PTPN22 (R620W) polymorphism with IBD in our patient population (see Table 1). In addition, no differences were observed in the distribution of genotypes between patients and healthy controls. Interestingly, our findings are in agreement with studies on Spanish [21,24] British [25] Northern German [26] Canadian [27] New Zealand [28] and Czech [29] populations, wherein this association was not registered.

This was also confirmed by the meta-analysis conducted by Latiano et al., showing a lack of association between the PTPN22 C1858T variant and the CD and UC phenotypes [30].

It should be noted that the absence of the homozygous genotype for the variant allele in our CD cohort is in accordance with its absence in Asian and African populations, with the polymorphic allele being most prevalent in Scandinavia [31].

On the other hand, our results are in disagreement with previous reports where it has been shown that the polymorphism of the PTPN22 (R620W) gene rather played a predisposing factor to IBD risk.

Sfar et al., argued for the association between PTPN22 $1858 \mathrm{~T}$ allele and susceptibility to IBD in Tunisian patients [32]. However, the absence of homozygous genotype for the variant allele is also found in this latter North African population. PTPN22 SNP has also been associated with colonic CD [33] in a Canadian cohort.

Otherwise, a genetically determined lower activity of the inflammatory gene PTPN22 $(620-\mathrm{W})$ was associated with reduced risk of CD and UC in a Danish Cohort [34]. 
In a similar way, Meta-analysis testing the overall effect of the PTPN22 620W variant pointed out an association with reduced risk of CD but not of UC [35].

To date it is thoroughly known that the frequency of the examined PTPN22 (R620W) variant varies between populations. Contradictory results have been published regarding the association of rs2476601 variant with either $\mathrm{CD}$ or UC. This inconsistency might be due to differences in sample size, selection bias or allele frequencies. Overall, there is inescapable evidence for the considerable effect of population stratification on case-control association studies.

Our study showed that frequency of the mutated allele is higher within IBD and particularly in UC patients compared to controls. However, although higher frequencies of the variant $1858 \mathrm{~T}$ allele were noticed, no significant difference in allelic distribution was identified in our case-control study.

The discrepancy between our findings and previous studies might be explained not only by the difference in minor allele distribution of PTPN22 rs2476601 in our population but also by the contribution of genetic factors in disease-related ethnic disparities. Those data further show the real difficulties encountered in analyzing candidate genes in complex diseases. Thereby, further well powered studies are needed to obtain a clear insight into the impact of the Protein Tyrosine Phosphatase Nonreceptor type 22 (PTPN22) on the immunogenetic and pathophysiological aspects of IBD.

\section{Materials and methods \\ Subjects}

Our study population consisted of 195 IBD [135 CD and $60 \mathrm{UC}$ ] patients recruited from the CHU Ibn Rochd Hospital (Casablanca, Morocco). The ethnically matched control group was described before [36] and comprises 311 unrelated healthy subjects with Moroccan origin. None of the control individuals had any evidence of autoimmune diseases.

Diagnosis of CD or UC was confirmed in accordance with the standardized set of clinical, radiological, endoscopic, and histological criteria [37]. Data obtained from each patient were collected in a case report form as previously described [38] and included age at diagnosis, disease location and phenotype, extra-intestinal manifestations, toxic behavior and other clinical features.

\section{Ethics statement}

All study participants provided written informed consent. The study was approved by the Ethics Committee of the Faculty of Medicine and Pharmacy of Casablanca and was conducted in accordance with the Declaration of Helsinki.

\section{Genotyping}

Genomic DNA samples were obtained from peripheral whole-blood using the salting-out method and from Formalin Fixed Paraffin Embedded Tissues using the QIAamp DNA FFPE Tissue Kit (Qiagen, Valencia, CA, USA). DNA concentration and quality were analyzed using a NanoDrop 1000 spectrophotometer (Thermo Fisher Scientific, Wilmington, DE, USA).

Genotyping of the PTPN22 SNP (rs2476601, 1858C $\rightarrow$ T, R620W) was performed using the TaqMan $5^{\prime}$-allele discrimination (predesigned TaqMan ${ }^{\mathrm{TM}}$ SNP Genotyping Assay by Applied Biosystems Catalog Number: 4351379) on the Light Cycler 480 System (Roche, Barcelona, Spain). The polymerase chain reaction (PCR) was carried out in a total reaction volume of $5 \mu \mathrm{l}$ with $0.01 \mu \mathrm{g} / \mu \mathrm{l}$ of genomic DNA, using the following cycling conditions: one cycle of $95{ }^{\circ} \mathrm{C}$ for $3 \mathrm{~min}$ followed by 50 cycles of $95^{\circ} \mathrm{C}$ for $3 \mathrm{~s}, 60$ ${ }^{\circ} \mathrm{C}$ for $20 \mathrm{~s}$, and cooled down to $4{ }^{\circ} \mathrm{C}$ for storage. To detect sequence variations the LightCycler ${ }^{\circledR} 480$ software release 1.5.0 SP4 version 1.5.0.39 was used.

\section{Statistical analysis}

Patients were grouped into CD, UC and all IBD subjects to determine differences in the minor allele frequencies between the different groups. Hardy-Weinberg equilibrium (HWE) assessment was done using the Pearson's Chi square test. Statistical power was calculated using Power Calculator of Genetic Studies 2006 software (http://www.sph.umich.edu/csg/abecasis/CaTS/). Allele frequency and genotype distribution were estimated for the disease compared to the control group based on $x^{2}$ analysis or Fisher's test. Descriptive statistical analysis has been performed using Plink software V1.07 (http://pngu. mgh.harvard.edu/purcell/plink/). Association analyses were applied to detect the associations with the candidate SNP and disease risk. The strength of association was estimated by calculation of the Relative risk/odds ratios (OR) and 95\% confidence intervals (CI). A P-value $<0.05$ was considered to be statistically significant.

\section{Limitations}

Although the capacity of the PTPN22 (R620W) variant to impair Lyp function strongly supports its relevance in the etiology of a subgroup of autoimmune diseases, the pathogenic inflammatory pathway is not always common between these disorders. Based on the evidence of this study and former reports, it is likely that the functional effect of this polymorphism is not a major contributing factor to IBD susceptibility in the Moroccan population.

In view of the possible confounders' effect on the present study, it is likely that due to small sample size, an association cannot be ruled out. Further well-powered studies would be required to confirm our findings. 


\begin{abstract}
Abbreviations
IBD: inflammatory bowel disease; CD: Crohn's disease; UC: ulcerative colitis: OR: odds ratios; PTPN22: protein tyrosine phosphatase non-receptor type 22; PTP: protein tyrosine phosphatase; LYP: Iymphoid-tyrosine phosphatase; SNP: single nucleotide polymorphism.
\end{abstract}

\section{Authors' contributions}

YZ and NS1 performed the majority of experiments, analyzed the data and wrote the paper. FZB and AS participated in the experiments. NS2 participated in the recruitment of patients. MO has significantly contributed to the improvement of this work and has been helpful to answer the referees. $Y Z$, MK, WB, JM and SN: designed and coordinated the research. All authors read and approved the final manuscript.

\section{Author details}

${ }^{1}$ Research Center of Abulcasis University of Health Sciences, Rabat, Morocco. ${ }^{2}$ Laboratory of Genetic and Molecular Pathology (LGPM), Faculty of Medicine and Pharmacy of Casablanca, Hassan II University, Casablanca, Morocco.

${ }^{3}$ Anatomical Pathology Laboratory, CHU Ibn Rochd, Casablanca, Morocco.

${ }^{4}$ Instituto de Parasitología y Biomedicina López-Neyra, Consejo Superior de Investigaciones Científicas, P.T.S. Granada, Granada, Spain. ${ }^{5}$ Gastroenterology Department, CHU IbnRochd, Casablanca, Morocco. ${ }^{6}$ Department of Biology, Immunology and Biodiversity Laboratory, Faculty of Sciences, Hassan II University, Casablanca, Morocco.

\section{Acknowledgements}

We thank the patients and clinical staff in the CHU Ibn Rochd hospital for their participation to this work.

\section{Competing interests}

The authors declare that they have no competing interests.

\section{Availability of data and materials}

The datasets supporting the conclusions of this article are included within the article.

\section{Consent to publish}

Not applicable.

\section{Ethics and consent to participate}

The ethics committee of the Faculty of Medicine and Pharmacy of Casablanca approved the study in accordance with the declaration of Helsinki for experiments involving humans, and a written informed consent was obtained from all participants.

\section{Funding}

This research did not receive any specific grant from funding agencies in the public, commercial, or not-for-profit sectors.

\section{Publisher's Note}

Springer Nature remains neutral with regard to jurisdictional claims in published maps and institutional affiliations.

Received: 16 May 2018 Accepted: 23 October 2018

Published online: 01 November 2018

\section{References}

1. Zallot C, Peyrin-Biroulet L. Deep remission in inflammatory bowel disease: looking beyond symptoms. CurrGastroenterol Rep. 2013;15(3):315.

2. Bouma G, Strober W. The immunological and genetic basis of inflammatory bowel disease. Nat Rev Immunol. 2003;3(7):521-33.

3. Karlinger K, Györke T, Makö E, Mester A, Tarján Z. The epidemiology and the pathogenesis of inflammatory bowel disease. Eur J Radiol. 2000;35(3):154-67.

4. Loddo I, Romano C. Inflammatory Bowel disease: genetics, epigenetics, and pathogenesis. Front Immunol. 2015;6:551.
5. Juyal G, Prasad P, Senapati S, Midha V, Sood A, Amre D, et al. An investigation of genome-wide studies reported susceptibility loci for ulcerative colitis shows limited replication in north Indians. PLoS ONE. 2011;6(1):e16565.

6. Rivas MA, Beaudoin M, Gardet A, Stevens C, Sharma Y, Zhang CK, et al. Deep resequencing of GWAS loci identifies independent rare variants associated with inflammatory bowel disease. Nat Genet. 2011;43(11):1066-73.

7. Cohen S, Dadi H, Shaoul E, Sharfe N, Roifman CM. Cloning and characterization of a lymphoid-specific, inducible human protein tyrosine phosphatase. Lyp. Blood. 1999;93(6):2013-24.

8. Cloutier JF, Veillette A. Association of inhibitory tyrosine protein kinase p50csk with protein tyrosine phosphatase PEP in T cells and other hemopoietic cells. EMBO J. 1996;15(18):4909-18.

9. Gomez LM, Anaya J-M, Gonzalez Cl, Pineda-Tamayo R, Otero W, Arango A, et al. PTPN22 C1858T polymorphism in Colombian patients with autoimmune diseases. Genes Immun. 2005;6(7):628-31.

10. Stanford SM, Rapini N, Bottini N. Regulation of TCR signalling by tyrosine phosphatases: from immune homeostasis to autoimmunity. Immunology. 2012;137(1):1-19.

11. Cloutier JF, Veillette A. Cooperative inhibition of T-cell antigen receptor signaling by a complex between a kinase and a phosphatase. J Exp Med. 1999;189(1):111-21.

12. Gregersen PK, Lee H-S, Batliwalla F, Begovich AB. PTPN22: setting thresholds for autoimmunity. Semin Immunol. 2006;18(4):214-23 (Epub 2006 May 30).

13. Begovich AB, Carlton VEH, Honigberg LA, Schrodi SJ, Chokkalingam AP, Alexander $\mathrm{HC}$, et al. A missense single-nucleotide polymorphism in a gene encoding a protein tyrosine phosphatase (PTPN22) is associated with rheumatoid arthritis. Am J Hum Genet. 2004;75(2):330-7 (Epub 2004 Jun 18).

14. Fiorillo E, Orrú V, Stanford SM, Liu Y, Salek M, Rapini N, et al. Autoimmuneassociated PTPN22 R620W variation reduces phosphorylation of lymphoid phosphatase on an inhibitory tyrosine residue. J Biol Chem. 2010;285(34):26506-18.

15. Burn GL, Svensson L, Sanchez-Blanco C, Saini M, Cope AP. Why is PTPN22 a good candidate susceptibility gene for autoimmune disease? FEBS Lett. 2011;585(23):3689-98 (Epub 2011 Apr 20)

16. van Oene M, Wintle RF, Liu X, Yazdanpanah M, Gu X, Newman B, et al. Association of the lymphoid tyrosine phosphatase R620W variant with rheumatoid arthritis, but not Crohn's disease. Canadian populations. Arthritis Rheum. 2005;52(7):1993-8.

17. Gaibar M, Esteban E, Harich N, Kandil M, Fernández-Santander A. Genetic differences among North African Berber and Arab-speaking populations revealed by Y-STR diversity. Ann Hum Biol. 2011;38(2):228-36 (Epub 2010 Sep 21).

18. Onengut-Gumuscu S, Ewens KG, Spielman RS, Concannon P. A functional polymorphism (1858C/T) in the PTPN22 gene is linked and associated with type I diabetes in multiplex families. Genes Immun. 2004;5(8):678-80.

19. Kyogoku C, Langefeld CD, Ortmann WA, Lee A, Selby S, Carlton VEH, et al. Genetic association of the R620W polymorphism of protein tyrosine phosphatase PTPN22 with human SLE. Am J Hum Genet. 2004;75(3):504-7.

20. Velaga MR, Wilson V, Jennings $C E$, Owen $C J$, Herington $S$, Donaldson PT, et al. The codon 620 tryptophan allele of the lymphoid tyrosine phosphatase (LYP) gene is a major determinant of Graves' disease. J Clin Endocrinol Metab. 2004;89(11):5862-5.

21. Criswell LA, Pfeiffer KA, Lum RF, Gonzales B, Novitzke J, Kern M, et al. Analysis of families in the multiple autoimmune disease genetics consortium (MADGC) collection: the PTPN22 620W allele associates with multiple autoimmune phenotypes. Am J Hum Genet. 2005;76(4):561-71.

22. Begovich AB, Caillier SJ, Alexander HC, Penko JM, Hauser SL, Barcellos $L F$, et al. The R620W polymorphism of the protein tyrosine phosphatase PTPN22 is not associated with multiple sclerosis. Am J Hum Genet. 2005;76(1):184-7.

23. Sahin N, Bicakcigil M, Atagunduz P, Direskeneli H, Saruhan-Direskeneli G. PTPN22 gene polymorphism in Behçet's disease. Tissue Antigens. 2007;70(5):432-4

24. Martín MC, Oliver J, Urcelay E, Orozco G, Gómez-Garcia M, López-Nevot MA, et al. The functional genetic variation in the PTPN22 gene has a 
negligible effect on the susceptibility to develop inflammatory bowel disease. Tissue Antigens. 2005;66(4):314-7.

25. Prescott NJ, Fisher SA, Onnie C, Pattni R, Steer S, Sanderson J, et al. A general autoimmunity gene (PTPN22) is not associated with inflammatory bowel disease in a British population. Tissue Antigens. 2005;66(4):318-20.

26. Wagenleiter SEN, Klein W, Griga T, Schmiegel W, Epplen JT, Jagiello P. A case-control study of tyrosine phosphatase (PTPN22) confirms the lack of association with Crohn's disease. Int J Immunogenet. 2005;32(5):323-4.

27. Van Oene M, Wintle RF, Liu X, Yazdanpanah M, Gu X, Newman B, et al. Association of the lymphoid tyrosine phosphatase R620W variant with rheumatoid arthritis, but not Crohn's disease, Canadian populations. Arthritis Rheum. 2005;52(7):1993-8.

28. Morgan AR, Han DY, Huebner C, Lam WJ, Fraser AG, Ferguson LR. PTPN2 but not PTPN22 is associated with Crohn's disease in a New Zealand population. Tissue Antigens. 2010;76(2):119-25.

29. Hradsky O, Lenicek M, Dusatkova P, Bronsky J, Nevoral J, Valtrova V, et al. Variants of CARD15, TNFA and PTPN22 and susceptibility to Crohn's disease in the Czech population: high frequency of the CARD15 $1007 \mathrm{fs}$. Tissue Antigens. 2008;71(6):538-47.

30. Latiano A, Palmieri O, Valvano MR, Bossa F, Latiano T, Corritore G, et al. Evaluating the role of the genetic variations of PTPN22, NFKB1, and FcGRIIIA genes in inflammatory bowel disease: a meta-analysis. Inflamm Bowel Dis. 2007;13(10):1212-9.

31. Mori M, Yamada R, Kobayashi K, Kawaida R, Yamamoto K. Ethnic differences in allele frequency of autoimmune-disease-associated SNPs. J Hum Genet. 2005;50(5):264-6.
32. Sfar I, Ben Aleya W, Mouelhi L, Aouadi H, Ben Rhomdhane T, Makhlouf M, et al. Lymphoid tyrosine phosphatase R620W variant and inflammatory bowel disease in Tunisia. World J Gastroenterol. 2010;16(4):479-83.

33. Waterman M, Xu W, Stempak JM, Milgrom R, Bernstein CN, Griffiths $\mathrm{AM}$, et al. Distinct and overlapping genetic loci in Crohn's disease and ulcerative colitis: correlations with pathogenesis. Inflamm Bowel Dis. 2011;17(9):1936-42.

34. Bank S, Skytt Andersen P, Burisch J, Pedersen N, Roug S, Galsgaard J, et al. Polymorphisms in the inflammatory pathway genes TLR2, TLR4, TLR9, LY96, NFKBIA, NFKB1, TNFA, TNFRSF1A, IL6R, IL10, IL23R, PTPN22, and PPARG are associated with susceptibility of inflammatory bowel disease in a Danish cohort. PLoS ONE. 2014;9(6):e98815.

35. Diaz-Gallo L-M, Espino-Paisán L, Fransen K, Gómez-García M, van Sommeren S, Cardeña C, et al. Differential association of two PTPN22 coding variants with Crohn's disease and ulcerative colitis. Inflamm Bowel Dis. 2011;17(11):2287-94.

36. Senhaji N, Serrano A, Badre W, Serbati N, Karkouri M, Zaid Y, et al. Association of inflammatory cytokine gene polymorphisms with inflammatory bowel disease in a Moroccan cohort. Genes Immun. 2016;17(1):60-5.

37. Lennard-Jones JE. Classification of inflammatory bowel disease. Scand J Gastroenterol Suppl. 1989;170:2-6-19.

38. Senhaji N, Kassogue Y, Fahimi M, Serbati N, Badre W, Nadifi S. Genetic polymorphisms of multidrug resistance gene-1 (MDR1/ABCB1) and glutathione S-transferase gene and the risk of inflammatory bowel disease among Moroccan patients. Mediators Inflamm. 2015;2015:248060.
Ready to submit your research? Choose BMC and benefit from:

- fast, convenient online submission

- thorough peer review by experienced researchers in your field

- rapid publication on acceptance

- support for research data, including large and complex data types

- gold Open Access which fosters wider collaboration and increased citations

- maximum visibility for your research: over $100 \mathrm{M}$ website views per year

At BMC, research is always in progress.

Learn more biomedcentral.com/submissions 